\title{
DRY LUBRICANT FILMS FOR ALUMINUM FORMING*
}

Jianjun Wei, Ali Erdemir, and George R. Fenske

Energy Technology Division

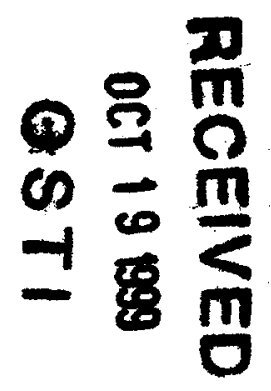

Argonne, IL 60439

\begin{abstract}
The submitted manuscript has been authored by a contractor of the U. S. Government under contract No. W-31-109-ENG-38. Accordingly, the U. S. Government

retains a nonexclusive, royalty-free license to publish or

allow orhers 10 do is for U. S. Government purposes.
\end{abstract}

February 1999

Paper for presentation at the 1999 STLE/ASME Tribology Conference, October 11-13, 1999, Kissimmee, Florida.

*Work supported by the U.S. Department of Energy, Office of Energy Research, under Contract W-31-109-Eng-38. 


\section{DISCLAIMER}

This report was prepared as an account of work sponsored by an agency of the United States Government. Neither the United States Government nor any agency thereof, nor any of their employees, make any warranty, express or implied, or assumes any legal liability or responsibility for the accuracy, completeness, or usefulness of any information, apparatus, product, or process disclosed, or represents that its use would not infringe privately owned rights. Reference herein to any specific commercial product, process, or service by trade name, trademark, manufacturer, or otherwise does not necessarily constitute or imply its endorsement, recommendation, or favoring by the United States Government or any agency thereof. The views and opinions of authors expressed herein do not necessarily state or reflect those of the United States Government or any agency thereof. 


\section{DISCLAIMER}

Portions of this document may be illegible in electronic image products. Images are produced from the best available original document. 


\title{
Dry Lubricant Films for Aluminum Forming
}

\author{
JIANJUN WEI, ALI ERDEMIR, and GEORGE R. FENSKE \\ Argonne National Laboratory, ET/212, 9700 S. Cass Avenue, Argonne, IL 60439
}

\begin{abstract}
During metal forming process, lubricants are crucial to prevent direct contact, adhesion, transfer and scuffing of workpiece materials and tools. Boric acid films can be firmly adhered to the clean aluminum surfaces by spraying their methanol solutions and provide extremely low friction coefficient (about 0.04). The cohesion strengths of the bonded films vary with the types of aluminum alloys (6061, 6111 and 5754). The sheet metal forming tests indicate that boric acid films and the combined films of boric acid and mineral oil can create larger strains than the commercial liquid and solid lubricants, showing that they possess excellent lubricities for aluminum forming. SEM analyses indicate that boric acid dry films separate the workpiece and die materials, and prevent their direct contact and preserve their surface qualities. Since boric acid is non-toxic and easily removed by water, it can be expected that boric acid films are environmentally friendly, cost effective and very efficient lubricants for sheet aluminum cold forming.
\end{abstract}

\section{KEY WORDS}

Boric Acid Dry Films, Aluminum Forming, Lubrication Mechanisms

\section{INTRODUCTION}

Aluminum and its alloys have been increasingly used in automotive components because they provide reduced weight and hence greater fuel economy, enhanced performance and recyclability while maintaining vehicle size and safety $[1,2]$. In aluminum forming operations, lubricants are crucial to prevent direct contact/adhesion of die and workpiece, and preserve the integrity of workpiece materials. It is well known that aluminum has a thin natural layer of aluminum oxide on the surface. The hard oxide 
coats may be broken during forming, the fresh surfaces are exposed and subject to adhesion and scuffing. The harder aluminum oxide layers abrade the surfaces of dies and tools. No lubrication or insufficient lubrication could cause excessive transfer of aluminum onto the harder tool surfaces, as well as scratches of aluminum surfaces and galling of tool surfaces. Commonly used lubricants are often flammable, contain active elements such as chlorine, sulfur and phosphorus that are potentially hazardous; and also often require volatile organic solvents to remove them from the formed surfaces. Postcleaning/disposal of these lubricants and solvents are difficult and costly $[3,4,5]$. It is therefore necessary to develop more suitable lubricants for metal forming process.

Our previous study indicated that boric acid is one of the best solid lubricants, which provides friction coefficient as low as 0.02 [6]. Friction tests revealed that boric acidbased compounds exhibit extremely low friction coefficients when applied to the surfaces of metals and ceramics. The chemical and structural analyses showed that the lubricating action of boric acid is due to its layered crystalline structure, in which the bonds between the layers are much weaker than the intralayer bonding [7]. The atomic layers of boric acid align themselves parallel to the sliding direction and slide easily over each other to provide low friction. Strong interatomic bonding and rigidity of layers prevent direct contact of two sliding bodies and thus avoid scuffing and /or galling.

More recent studies in our laboratory revealed that boric acid has strong tendency to form chemically bonded films on the oxidized surfaces of aluminum and its alloys. Water and methanol solutions of boric acid can be used to prepare bonded layers on aluminum surfaces [8]. These findings increased the prospect of developing boric acid as an effective lubricant for aluminum cold forming. In this study, we prepared boric acid films on three aluminum alloys $(6061,6111$ and 5754) and then investigated their cohesion strengths by friction lifetime tests on a pin-on-disk tester. We used a commercial metal forming test machine to evaluate the lubricating performance and usefulness of these bonded films. Under the same test conditions we also compared two commercial liquid lubricants currently used for aluminum forming as well as typical solid lubricants such as graphite, boron nitride (BN) and polytetrafluoroethylene (PTFE). Finally, the lubrication 
mechanisms of boric acid dry films and their bonding natures on aluminum alloys were discussed.

\section{EXPERIMENTAL DETAILS}

\section{Test Materials}

For the metalforming tests, three aluminum alloys $(6061,6111$ and 5754) were used to conduct the metal forming lubrication tests. Their chemical compositions are listed in Table 1. The dimension of 6061 sheet is $240.0 \times 25.4 \times 1.5 \mathrm{~mm}^{3}$. The dimensions of 6111 and 5754 sheets are $280.0 \times 25.4 \times 1.0 \mathrm{~mm}^{3}$. Before coated with lubricants, the sheets were cleaned and degreased with commonly used dish-washing detergent.

TABLE 1 - THE TYPICAL CHEMICAL COMPOSITIONS OF ALUMINUM ALLOYS USED IN THIS STUDY

\begin{tabular}{|c|c|c|c|c|c|c|c|}
\hline \multirow{2}{*}{ Trade code } & \multirow{2}{*}{ Grade } & \multicolumn{6}{|c|}{ Composition (wt\%) } \\
\hline & & $\mathrm{Mg}$ & $\mathrm{Si}$ & $\mathrm{Mn}$ & $\mathrm{Cu}$ & $\mathrm{Cr}$ & $\mathrm{Fe}$ \\
\hline 6061 & 0 & 1.0 & 0.6 & 0.15 & 0.30 & 0.2 & $\leq 0.7$ \\
\hline 6111 & $\mathrm{~T} 4$ & 0.77 & 0.63 & & 0.77 & & 0.25 \\
\hline 5754 & $\mathrm{O}$ & 3.1 & 0.06 & 0.25 & & & 0.20 \\
\hline
\end{tabular}

For standard ball-on-disk experiments, we used M50 bearing balls with a diameter of $9.55 \mathrm{~mm}$ and boric acid coated aluminum disks (6061, 6111 and 5754 alloys). The bearing balls were highly polished with a surface roughness of less than $0.01 \mu \mathrm{m}$ center- 
line-average (CLA). The hardness of the ball was about 61 in the Rockwell C scale. The aluminum disks were ground to about $0.2 \mu \mathrm{m}$ CLA. The ball was ultrasonically cleaned in acetone bath for 10 minutes and the disks were cleaned by the detergent. They were dried before storing in a desiccator until the actual tests or surface treatment.

The saturated methanol solutions of boric acid were prepared to spray and form dry boric acid films on the cleaned aluminum surface. The dry films were obtained after a few minutes evaporation of methanol solvent. The deposition amount of boric acid on the aluminum sheet is about $0.46 \mathrm{mg} / \mathrm{cm}^{2}$. The combined films of boric acid and mineral oil were made through brushing a layer of mineral oil on the boric acid dry films. The other selected lubricants include mineral oil, commercial solid lubricants (graphite, hexagonal $\mathrm{BN}$ and PTFE) and two commercial oil lubricants (Lube $\mathrm{A}$ and Lube B), which are mixture of fatty acids, oxyalkylated alcohol, alkylesters and other different constituents. The dry films of PTFE and BN were prepared by spraying their suspensions. The oil films of mineral oil and two commercial oil lubricants as well as the dry film of graphite were made through simply brushing process.

\section{Test Procedures}

Sliding friction tests were performed on a ball-on-disk test machine for examining the lubricities and lubrication lifetimes of boric acid films on three aluminum alloys. The schematic illustration of contact geometry of pin-on-disk test apparatus is shown in Figure 1. Once the boric acid films were worn out, the friction coefficient would be increased dramatically. The transition point can be used to judge the lubrication lifetimes and cohesion strengths of boric acid films on the aluminum surfaces. All the tests were run under a normal load of $10 \mathrm{~N}$ (corresponding to initial maximum contact stress of 0.41 $\mathrm{GPa}$ ) at a sliding speed of $0.01 \mathrm{~m} / \mathrm{s}$ at room temperature (about $20^{\circ} \mathrm{C}$ ). The relative humidity was controlled at $40 \%$.

Metal forming tests were performed by a commercial Interlaken test machine whose main features and test procedures were described in details in references $[9,10]$. It was 
used to measure relative friction and rank sheet metal forming lubricants. A schematic illustration of this tester is shown in Figure 2. It uses a short stroke clamping actuator and two dimensional tooling that allows the die to be opened and the workpiece was punched up to a limited stroke. The aluminum sheet was firmly clamped around the edges of the stretching punch and the shape was developed entirely at the expense of sheet thickness. Therefore, thinning, necking and even fracture of the aluminum sheet must eventually occur. Before testing, two parallel lines of $12.7 \mathrm{~mm}$ were scribed in the center area of the sheet. By measuring the scribe before and after testing, the strain of sheet forming was obtained. All tests were done at a punch rising rate of $1.0 \mathrm{~mm} / \mathrm{s}$. The maximum strain can be obtained when the sheet is broken as the punch goes up. In addition, extensometer was used to automatically measure the strain and loading profiles as a function of displacement of die at a fixed stroke. At least three tests were run under each condition to check the reproducibility of the aluminum forming. The maximum test error was labeled in these Figures. Scanning electron microscopy (SEM) was used to analyze the surface morphology of boric acid films and their substrates before and after forming tests.

\section{RESULTS AND DISCUSSION}

\section{Friction Tests}

In order to investigate the lubricity and bonding strength of boric acid dry films on aluminum alloys, ball-on-disk friction tests were run under severe test conditions (load: $10 \mathrm{~N}$, speed: $0.01 \mathrm{~m} / \mathrm{s}$ ) until the films were worn out, i.e. the friction coefficient is suddenly increased to a high level. The test results are shown in Figure 3. It is clear that boric acid films provide extremely low friction coefficients (about 0.04 ) for three aluminum alloys, which are lower than other solid lubricants such as graphite and molybdenum disulfide. Once the dry films are removed away, the friction coefficients are quickly increased up to 0.6. Subsequently, severe scuffing and aluminum transfer occur on the contact areas of the disks and balls. In addition, the lubrication lifetime on 5754 alloy is much longer than those on 6061 and 6111 alloys, which means that the cohesion strength of boric acid on 5754 is much stronger than the other two alloys. The cohesion 
strength of 6111 is slightly higher than that of 6061 . The different bonding behaviors may be related to the different surface chemistry of the alloys caused by alloying elements.

\section{Metalforming Tests}

Figure 4 shows the maximum strains for 6061 alloys under different lubricated conditions. In dry forming, the maximum strain of 6061 sheet is lowest $(0.60 \mathrm{~mm})$. Two commercial oil lubricants (Lube A and Lube B) create larger strains than dry forming and show very close lubricities. Relative to the two commercial lubricants, mineral oil and graphite are not good lubricants for 6061 forming, but BN, especially PTFE, are very good lubricants. Boric acid dry films alone have the same lubricating actions as the commercial lubricants. The combination of boric acid and mineral oil exhibits much better lubricity, whose strain ranks the highest among the tested lubricants. The result indicates that mineral oil may reduce the internal resisting force of boric acid films and increase their lubricities.

Figure 5 shows the maximum strains for 6111 alloys under different lubricated conditions. Similar trends as shown in Figure 4 are found for the ranking of lubricants. It is interesting that either boric acid dry films alone or their combined films have better lubricities than the two commercial lubricants, because they create larger strains. PTFE shows the best lubricating performance for 6111 forming.

Figure 6 presents the maximum strains for 5754 alloys under different lubricated conditions. There are similar trends for the ranking of lubricants as shown in Figure 5. It is remarkable that boric acid and its combined films show the highest strains among the test lubricants, indicating that they provide the best lubricities for 5754 forming.

Based on the above tests, we found that boric acid dry films and their combined films with mineral oils can provide larger strain distributions than the commercial liquid and solid lubricants, indicating that they are very good lubricants for aluminum cold forming. The lubricating performances of boric acid films vary with the types of aluminum alloys, 
which are related to their bonding strengths on the alloys. The bonding strength of boric acid film on 5754 is stronger than those on the other two alloys and therefore show the best lubricities among the 5754 forming lubricants.

Figure 7 gives the strain profiles as a function of displacement of die for 6111 alloys under boric acid and Lube A film lubrication. It is found that both strains are increased gradually with increasing the displacement. The strain difference between boric acid and Lube A becomes larger as the displacement is increased. Therefore, it is important to specify the stroke of die for a giving sheet forming test.

It is noted that thickness of 6061 alloy is different from the other two alloys $(1.5 \mathrm{~mm}$ for $6061,1.0 \mathrm{~mm}$ for 6111 and 5754), thus it is difficult to compare their intrinsic ductilities in dry forming. For 6111 and 5754 with the same thickness, 6111 is more easily stretched than 5754 in unlubricated forming operations. But both formabilities turn to very close values under lubricated conditions. It is also noted that PTFE and BN are very effective for aluminum alloy forming comparing to the commercial lubricants. However, there are difficulties in removing them from the workpiece surfaces. Similar phenomena also appeared for other solid lubricants such as wax, soap and acrylic [2, 3]. In contrast to these dry films, boric acid films can be very easily washed away by water or rinsed clean on a water jet. It is known that boric acid has high water solubility of about 5 grams per $100 \mathrm{ml}$ of water at $20^{\circ} \mathrm{C}$ and its solubility is increased with increasing temperature. Therefore, the application of boric acid films does not require costly postcleaning process.

\section{SEM Analysis}

Visual investigations show that boric acid films can be firmly bonded to the aluminum surfaces before and after forming. Figure 8 shows the SEM micrographs of 5754 alloy sheets before and after forming tests. Compared with original surface (Figure 8 (a)), the contact areas after dry forming are severely deformed, on which scratches and ploughing are formed (Figure $8(\mathrm{~b})$ ). The as-deposited boric acid dry films are densely distributed on 
the 5754 strip (Figure 8 (c)). After forming tests, the deformed areas are still covered with dense, layered dry films and no exposed substrate surfaces are found (Figure 8 (d)). A higher magnification picture shows that boric acid films are stretched during forming and show their intrinsic layer structures, which align themselves parallel to the direction of sliding (Figure 8 (e)). These pictures demonstrate that boric acid dry films can be firmly adhered to aluminum surfaces and therefore effectively prevent direct contact, adhesion, scuffing and transfer of aluminum alloys and die surfaces.

\section{Lubrication Mechanism of Boric Acid Films}

Friction and metal forming tests demonstrated that boric acid films show excellent lubricities for aluminum alloys. The lubrication nature of boric acid can be explained as follows. As elucidated in previous research articles $[6,7]$, boric acid crystallized in a layered triclinic crystal structure (see Figure 9). The atoms on each layer are closely packed and strongly bonded to each other. The atomic layers themselves are $0.318 \mathrm{~nm}$ apart from each other and held together by weak van der Waals forces. In a sense, the layered crystal structure of boric acid is similar to those of $\mathrm{MoS}_{2}$ and graphite. Therefore, the very slippery nature of boric acid is controlled by its layered crystal structure. Under shear stress of sliding contact, the crystalline layers align themselves parallel to the direction of relative motion, and slide over one another with relative ease. This mechanism is evidently consistent with the SEM observation as shown in Figure 8 (e).

\section{Discussion}

Previous studies indicated that boric acid is a very effective solid lubricant for ceramic and metallic materials $[7,11,12]$. In addition, boric acid could be successfully used in cutting and grinding fluids as additives for friction and corrosion control [13, 14], as well as in drilling fluid as an individual lubricant for increasing the removal rate of polycrystalline alumina [15]. In this study, the metal forming tests demonstrate that either boric acid dry films alone or their combined films with mineral oils can significantly 
increase the strains of aluminum alloys, indicating that they can also be used as aluminum cold forming lubricants.

The effectiveness of boric acid in aluminum forming operations may be due to two aspects, one is the layered crystal structure of boric acid itself, which provides easily sheared layers and low friction, another is the bonding of boric acid films on aluminum surfaces. Before aluminum forming, the as-deposited boric acid films appear to be strongly adhered to the aluminum surfaces, which are hardly removed away by vibration or finger touch. The good affinity of boric acid on aluminum surface may be related to their crystal structures. Both the boric acid and aluminum oxide have some ionic bond features, boric acid molecules may be chemically bonded to the aluminum oxide surfaces in the form of chemisorption. Detailed fundamental understandings of bonding nature between boric acid and naturally oxidized surfaces of aluminum alloys remain further study. During aluminum forming, there is possibility of chemical reactions occurring between boric acid and aluminum oxide because of very high shear stress and frictional temperature in the deformed area. Liang et al found that, in the drilling operations, boric acid solution interacts with the amorphous oxide grain boundary phase in the polycrystalline alumina, and promotes intergranular fracture and forms soluble aluminum containing compounds [15]. SEM investigations indicate that boric acid films are very firmly adhered to the deformed surfaces (see Figure 8 (d)). This may be related to tribochemical reactions between boric acid and aluminum surface. Whether or not these tribochemical reactions take place needs to be further clarified.

Friction tests indicate that the lubrication lifetime or bonding strength of boric acid films varies with the types of aluminum alloys. This implies that alloying elements may significantly affect the bonding natures of boric acids on the aluminum surfaces. It is clear that boric acid can be much more strongly bonded to 5754 (Al-Mg alloy) than 6061 and 6111 (Al-Mg-Si alloys). Considering that 5754 possess higher magnesium content than the other alloys, we prepared boric acid films on a pure cubic Mg block (purity: 99.9 $\%$ ) and measured the lubrication lifetime of boric acid films on the pure Mg surface. The friction tests were run under the same conditions as for other aluminum alloys. It is noted 
that the initial maximum contact stress on magnesium surface is $0.33 \mathrm{GPa}$, which is slightly lower than that of aluminum surface. The friction coefficient of steel ball against $\mathrm{Mg}$ block is similar to those for aluminum alloys (about 0.04 ), but it is surprising that the lubrication lifetime of boric acid film on $\mathrm{Mg}$ surface is much longer than those for aluminum alloys. The tests run steadily for 42480 seconds (11.8 hours) without any obvious change of friction coefficients until we stopped them. This finding indicates that the magnesium plays crucial role in the bonding of boric acid films on aluminummagnesium alloys. Similar to pure aluminum, magnesium is a very active metal and is very easily oxidized in the air, forming a layer of oxide coat. Therefore, boric acid films are actually bonded to the magnesium oxide either for pure magnesium or for $\mathrm{Al}-\mathrm{Mg}$ alloys. According to the long-term friction test results, we can anticipate that boric acid films may react with magnesium oxide and form lubricious tribochemical reaction products, which are responsible for the long term low friction behavior and for strong bonding with 5754 alloy. The tribochemical mechanisms between boric acid and magnesium are currently been studying in our laboratory. It is noted that the other alloying elements such as $\mathrm{Si}$ may also affect the bonding behaviors of boric acid films on aluminum alloys, although they only take a very small percentage in the alloys.

\section{SUMMARY}

Metal forming operations require lubricants prevent seizure and material transfer and secure the surface quality of workpiece. A suitable lubricant should be non-flammable, environmentally safe, easy apply and removal. In this study, we developed boric acid dry films for aluminum cold forming lubrication, which meet above requirements. Boric acid can be firmly bonded to the aluminum alloys by a simply spraying process. These films provide extremely low friction coefficient (about 0.04 ) for steel/aluminum contacts. These films also have different cohesion strengths and lubrication lifetimes on different aluminum alloys (6061, 6111 and 5754 alloys). Sheet forming tests demonstrate that boric acid dry films and their combined films with mineral oils possess better lubricities than the commercial oil lubricants. SEM analyses on 5754 alloys indicate that, under boric acid lubrication, the contact areas of sheets are covered with bonded layered 
lubricant films, and no exposed substrate surfaces were found after forming. The low friction natures of boric acid films are due to their layered crystal structures.

\section{ACKNOWLEDGEMENTS}

This work was supported by the U.S. Department of Energy, Office of Energy Research, under Contract W-31-109-Eng-38. The authors are also grateful for Mr. Richard Lee at Tribology Section, Argonne National Laboratory, for his help in sample preparation and SEM operation.

\section{REFERENCES}

(1) Fekete, J. R., "Overview of sheet metals for stamping", SAE Publication No. SP1221, pp 125-137, (1997).

(2) Story, J. M., Jarvis, G.W., Zonker, H. R. and Murtha, S. J., "Issues and trends in automotive aluminum sheet forming", SAE Publication No. SP-944, pp 1-25, (1993) .

(3) Schey, J. A., Tribology in metalworking-friction, lubrication and wear, American Society for Metals, Metals Park, Ohio, (1983).

(4) Lazzarotto, L., Dubar, L., Dubois, A., Ravassard, P., Bricout, J. P. and Oudin, J., “A selection methodology for lubricating oils in cold metal forming processes", Wear, 215 , pp 1-9, (1998).

(5) Nachtman E. S. and Kalpakjian, S., Lubricants and lubrication in metalworking operations, Marcel Dekker, Inc., New York and Basel, (1985).

(6) Erdemir, A., Erck R. A. and Robles, J., "The relation of hertzian contact pressure to friction behavior of self-lubricating boric acid films", Surface Coatings and Technology, 49, p 435, (1991).

(7) Erdemir, A., "Tribological properties of boric acid and boric-acid-forming surfaces. Part I: Crystal Chemistry and mechanism of self-lubrication of boric acid", Lubrication Engineering, 47, pp 168-173, (1991).

(8) Erdemir, A. and Fenske, G. R., "Clean and cost-effective dry boundary lubricants for aluminum forming", SAE Publication No. SP-1350, pp 9-17, (1998). 
(9) Houcque D. and Dampts, A. E., "New standard draw scale simplifies lubricant ranking", Metalforming Magazine, October, (1996).

(10) Harycki, R. M., Gasper,K. E., Smola, R. J., Saunders, F. I., Garrett J. M. and Wagoner, R. H., "A new method for ranking sheet metal lubricants", Metalforming Magazine, November, (1994).

(11) Erdemir, A., "Review of the lubrication of ceramics with thin solid films", Friction and Wear of Ceramics, S. Jahanmir, ed., Marcel Dekker, New York, NY, pp 119-162, (1994).

(12) Peterson, M. B., Murray, S. F. and Florek, J. K., "Consideration of lubricants for temperatures above 1000 F', ASLE Trans., 2, pp 225-234, (1960).

(13) Branneen, W. T., Burt G. D. and McDonald, R. A., "Phosphite amine lubricant for metal working and machining", U.S. Patent No. 4965002, (1990).

(14) Rekow, E. D., Zhang, G. M., Thompson V. P. and Jahanmir, S., "Fractorial design technique to investigate the effect of machine tool parameters and machining environment on surface finish", J. Dent. Research, IADR Abstract 570, (1993).

(15) Liang $\mathrm{H}$. and Jahanmir, S., "Boric acid as an additive for core-drilling of alumina", J. of Tribology, 117, pp 65-73, (1995). 


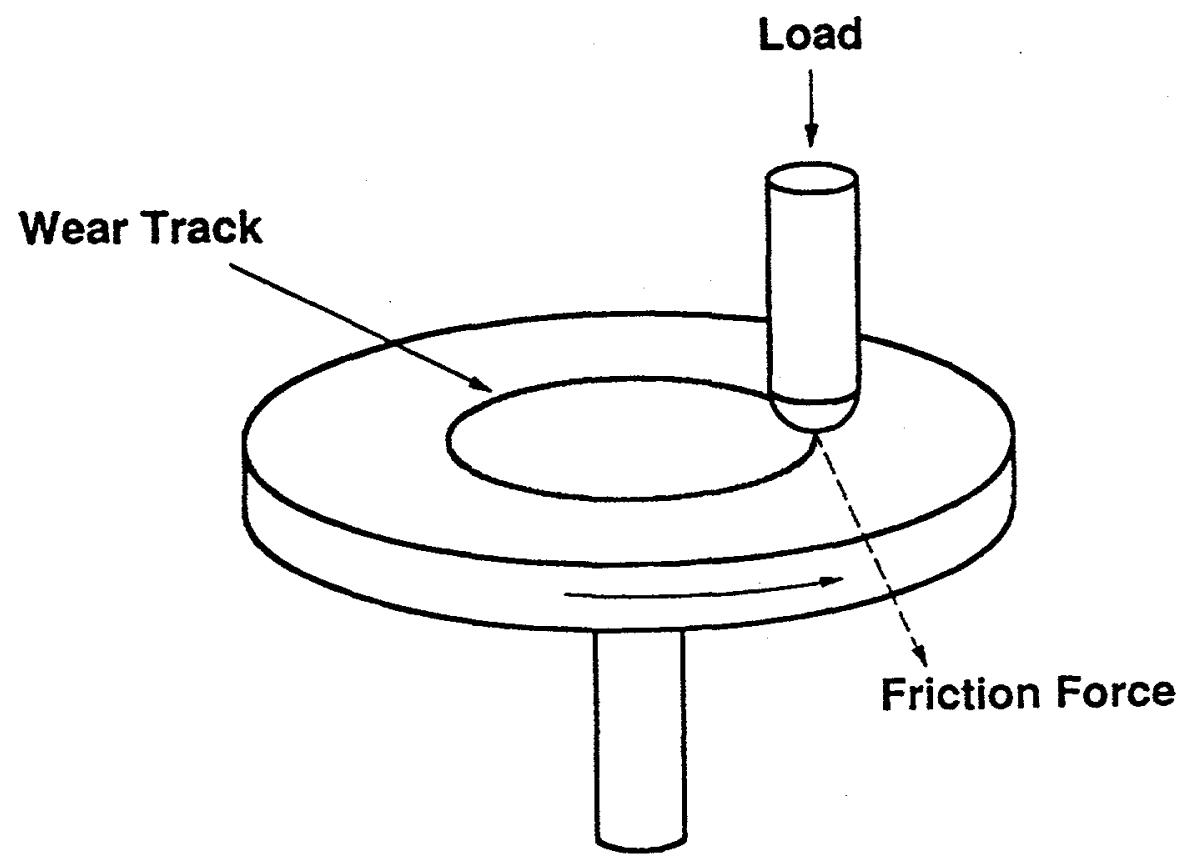

Figure 1 Schematic illustration of contact geometry of pin-on-disk test apparatus 


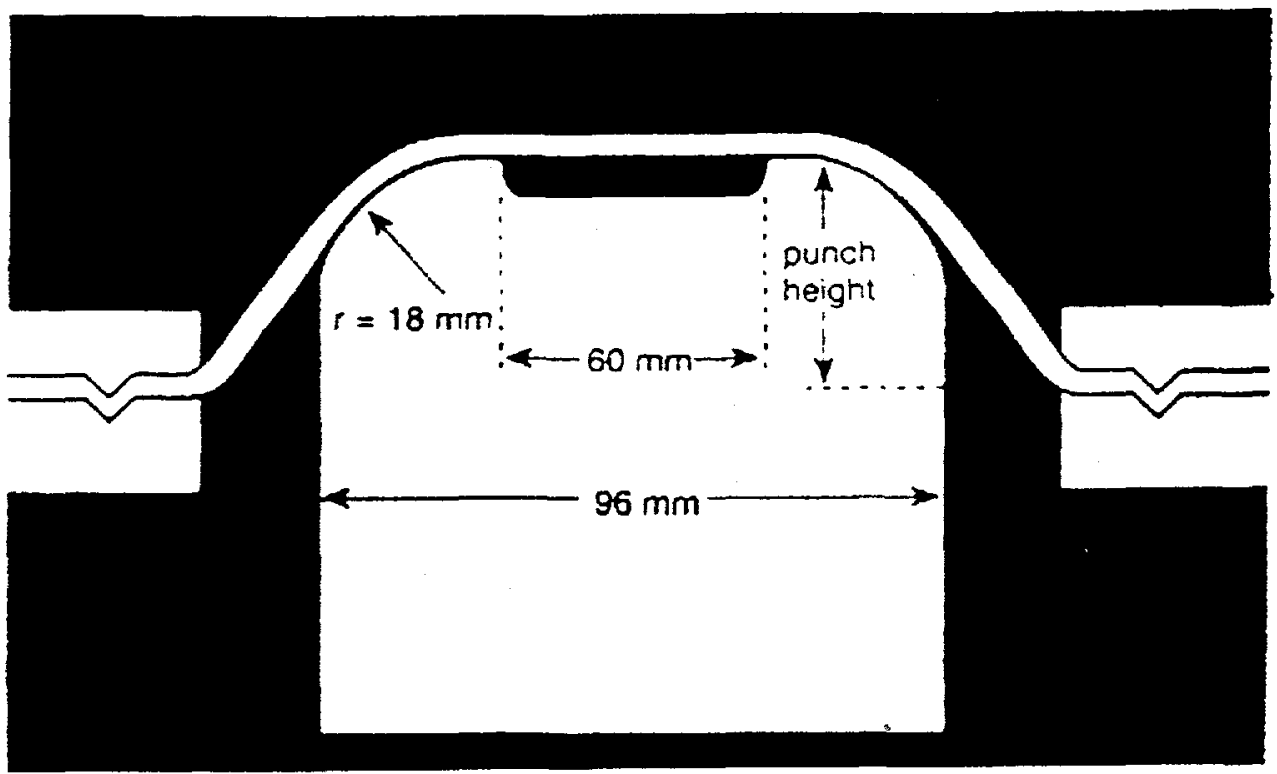

Figure 2 Schematic illustration of metal forming test machine 
Figure 3 The friction coefficient curves of steel balls against aluminum disks under boric acid lubrication

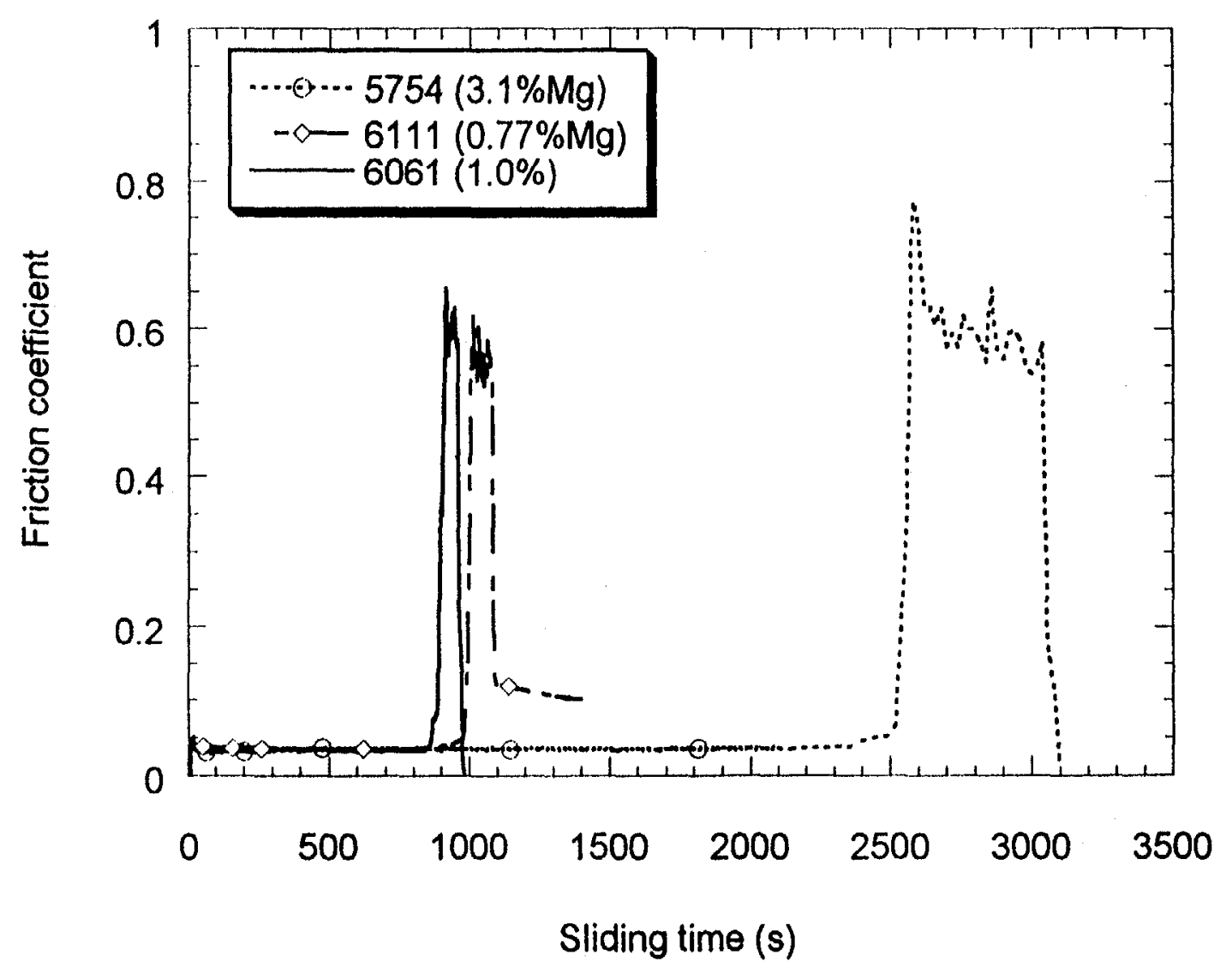




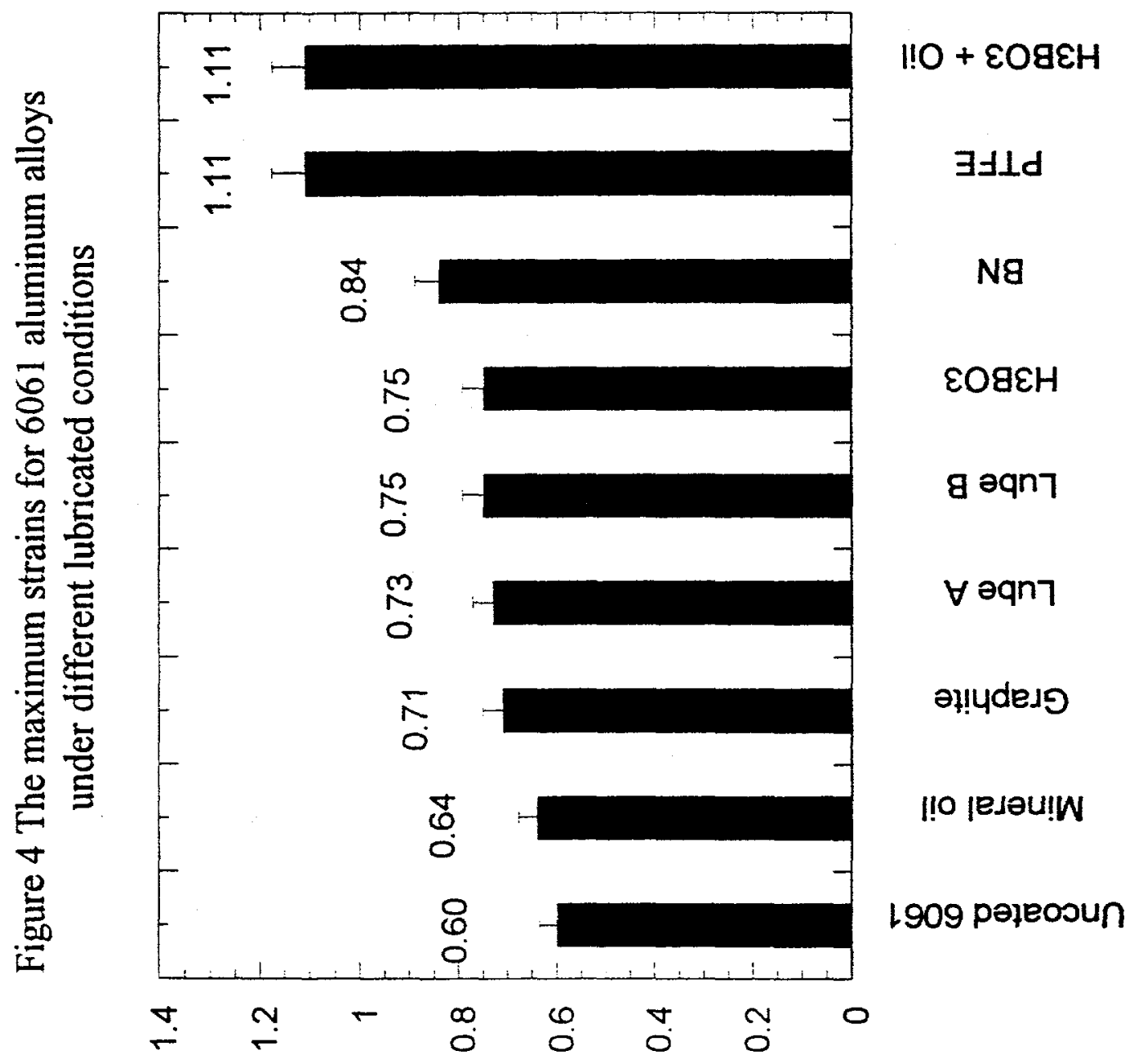

(um) ulests unurxew 


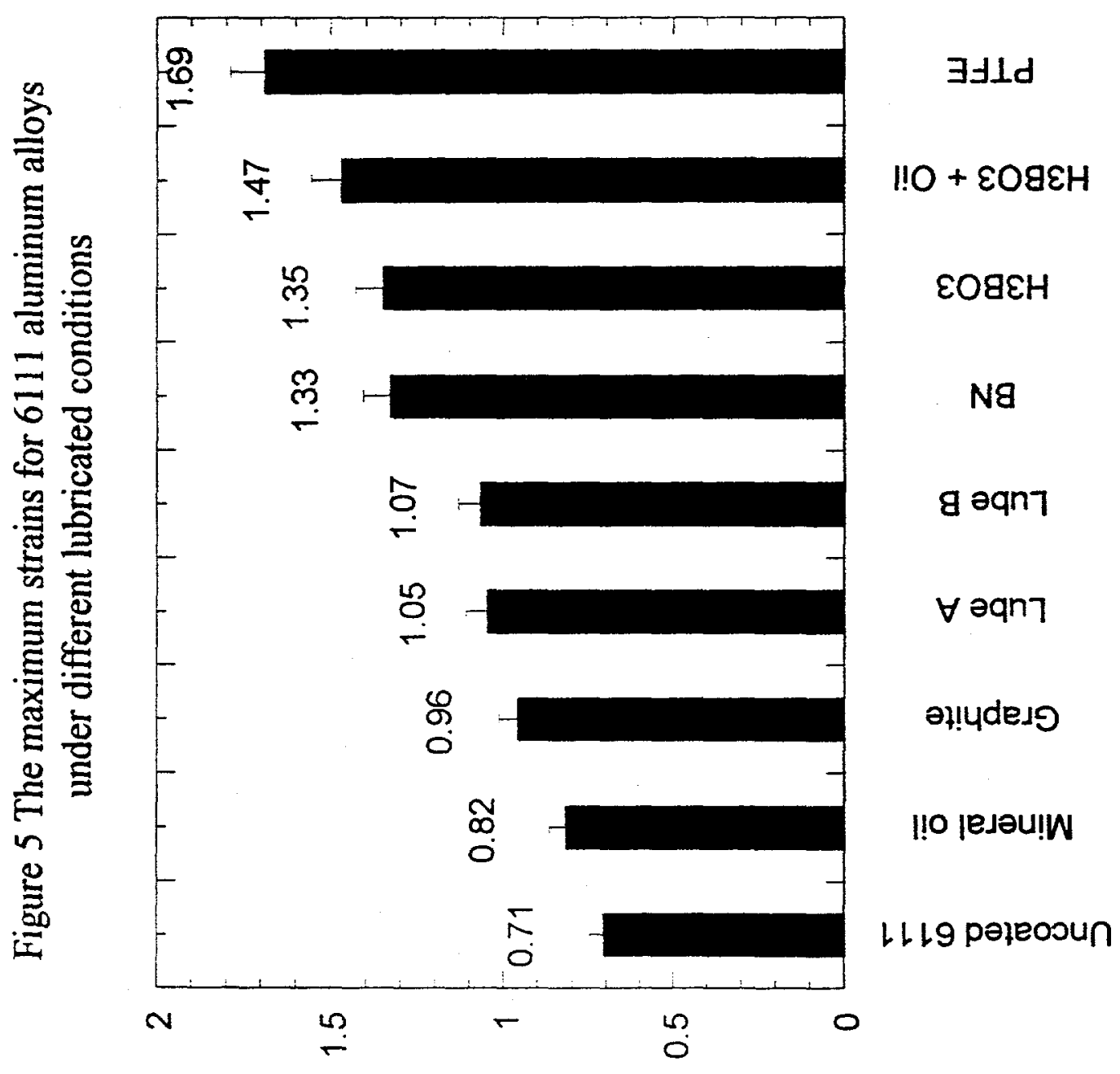

(wu) u!ełs wnu!x!W 
Figure 6 The maximum strains for 5754 aluminum alloys under different lubricated conditions

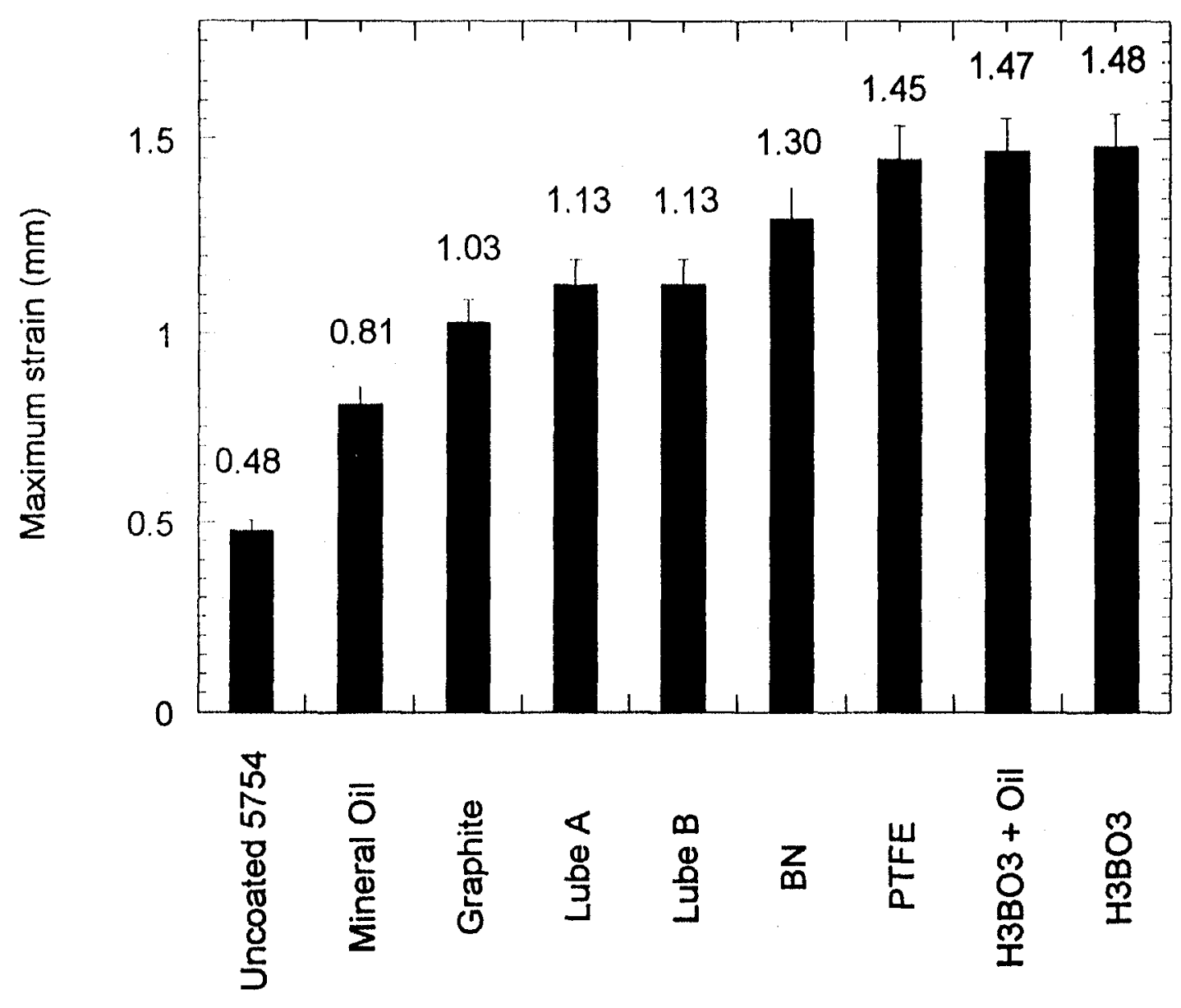


Figure 7 The strains of $\mathrm{Al}$ alloys (6111) as functions of displacements under boric acid and Lube A lubricated conditions (Stroke: $35 \mathrm{~mm}$, Thickness: $1.0 \mathrm{~mm}$, Punch rate: $1.0 \mathrm{~mm} / \mathrm{s}$ )

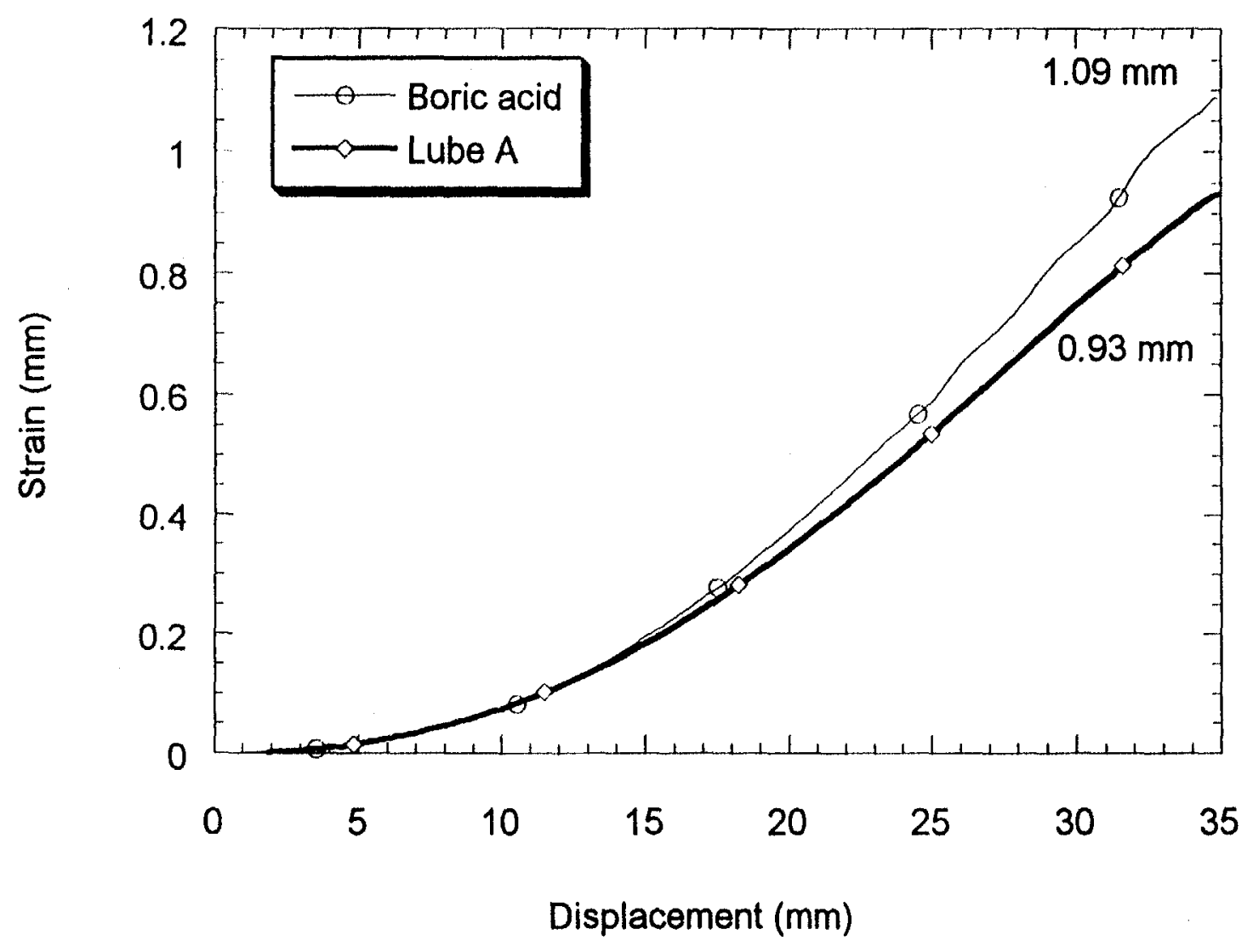




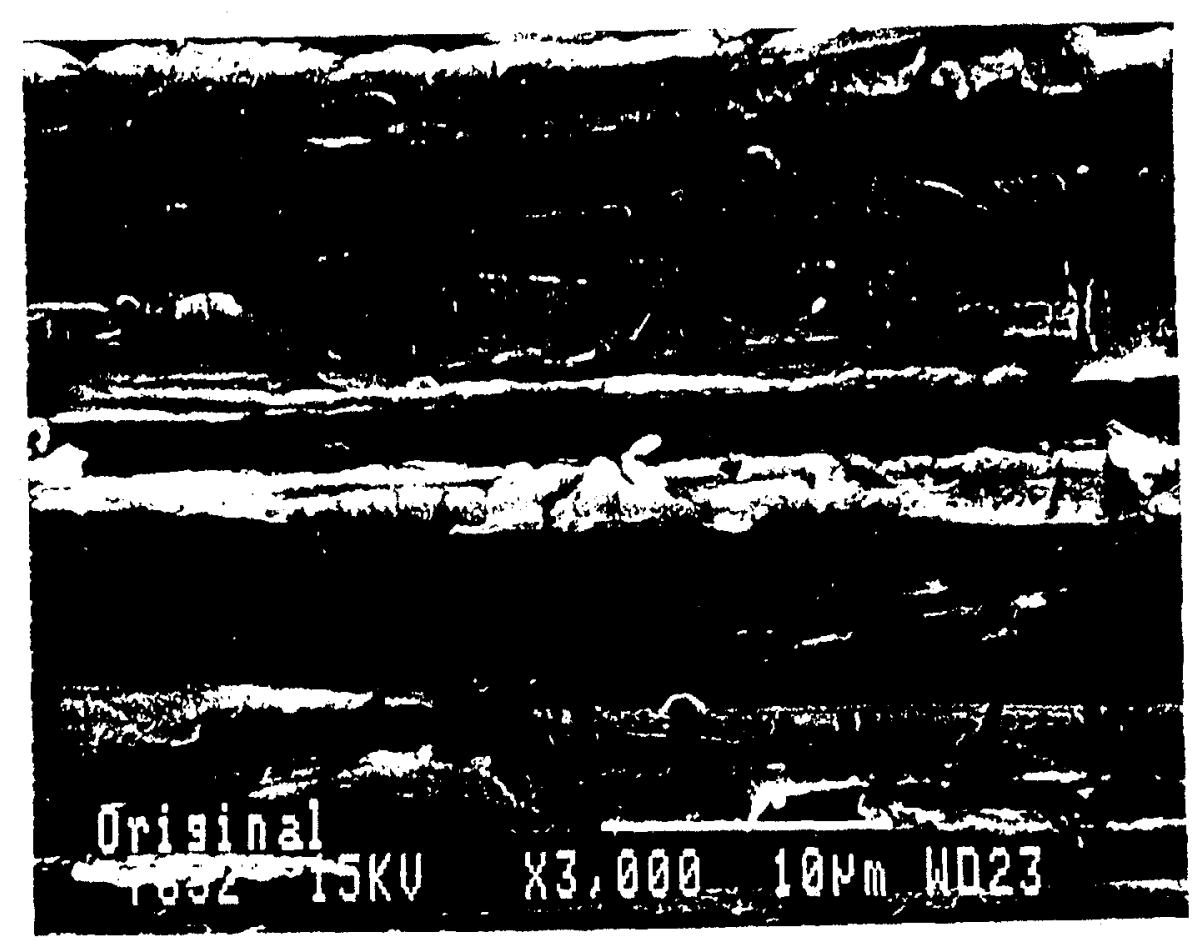

Fig.8 (a) Al strip before forming 


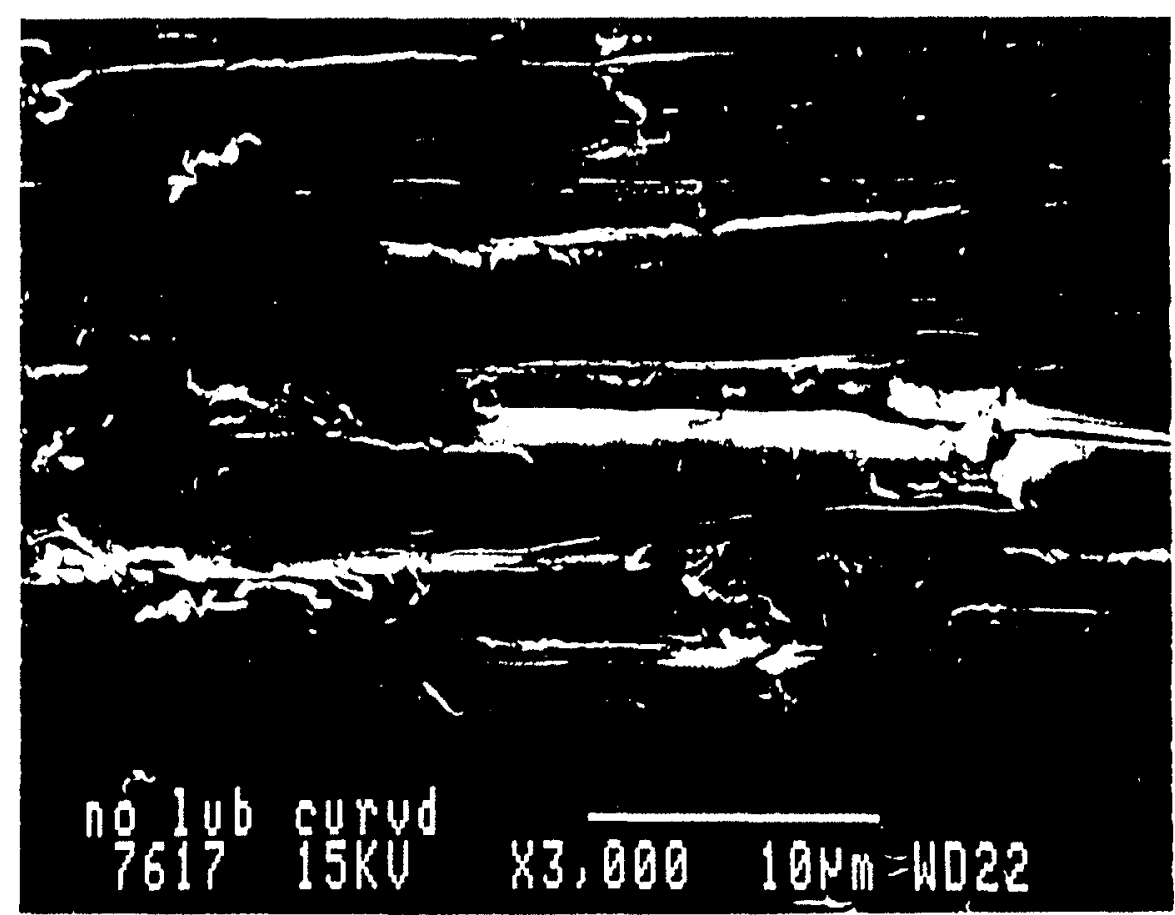

Fig. 8 (b) Al strip after forming 


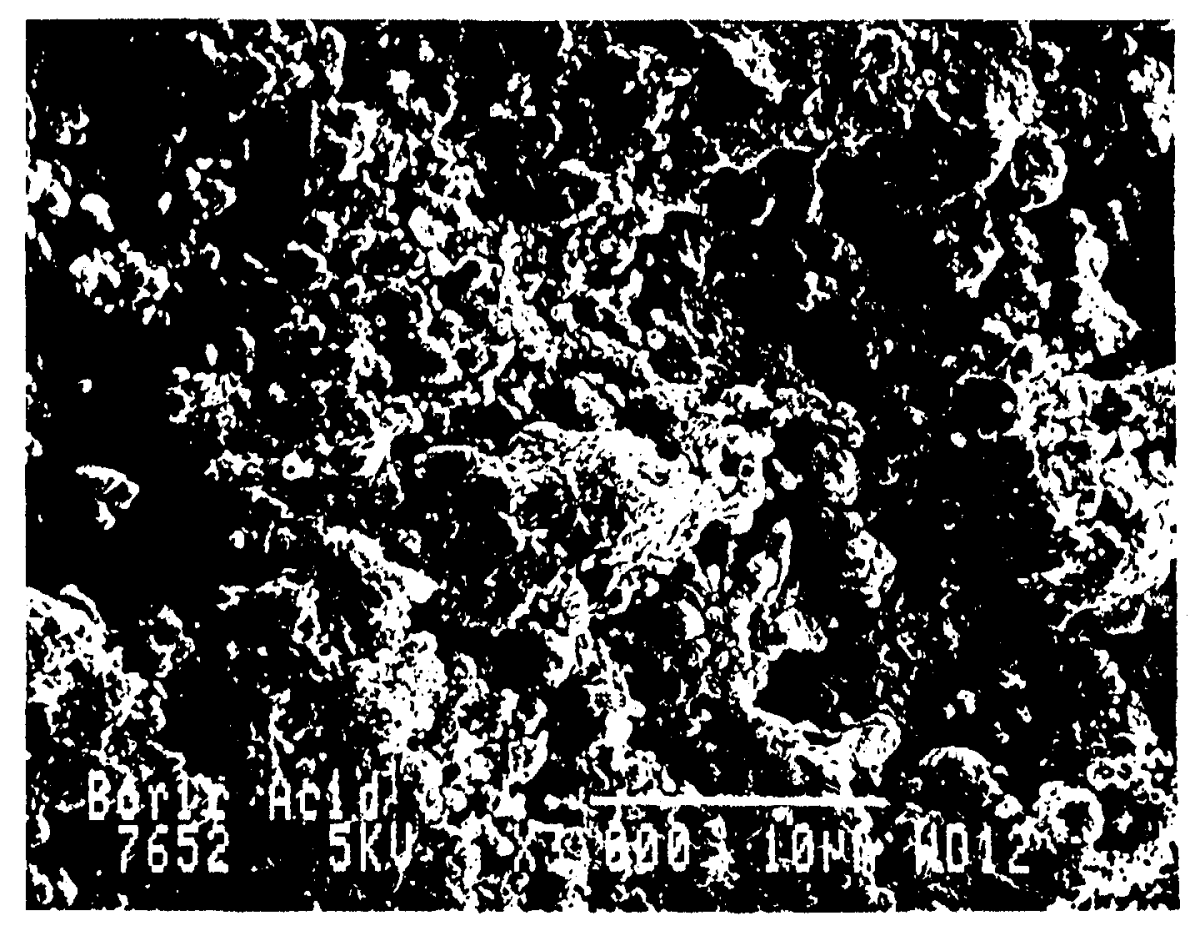

Fig. 8 (c) $\mathrm{H}_{3} \mathrm{BO}_{3}$ as-deposited on $\mathrm{Al}$ strip 


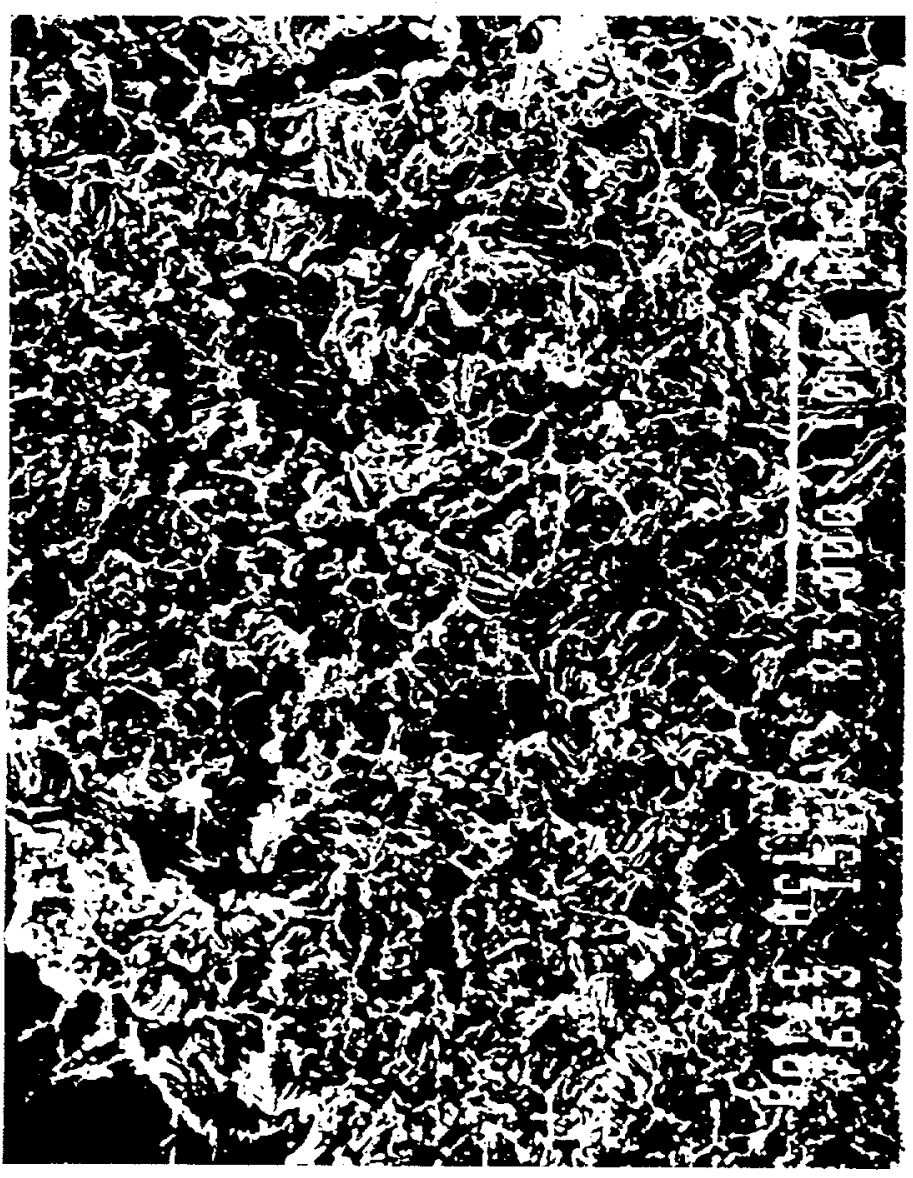

葛 


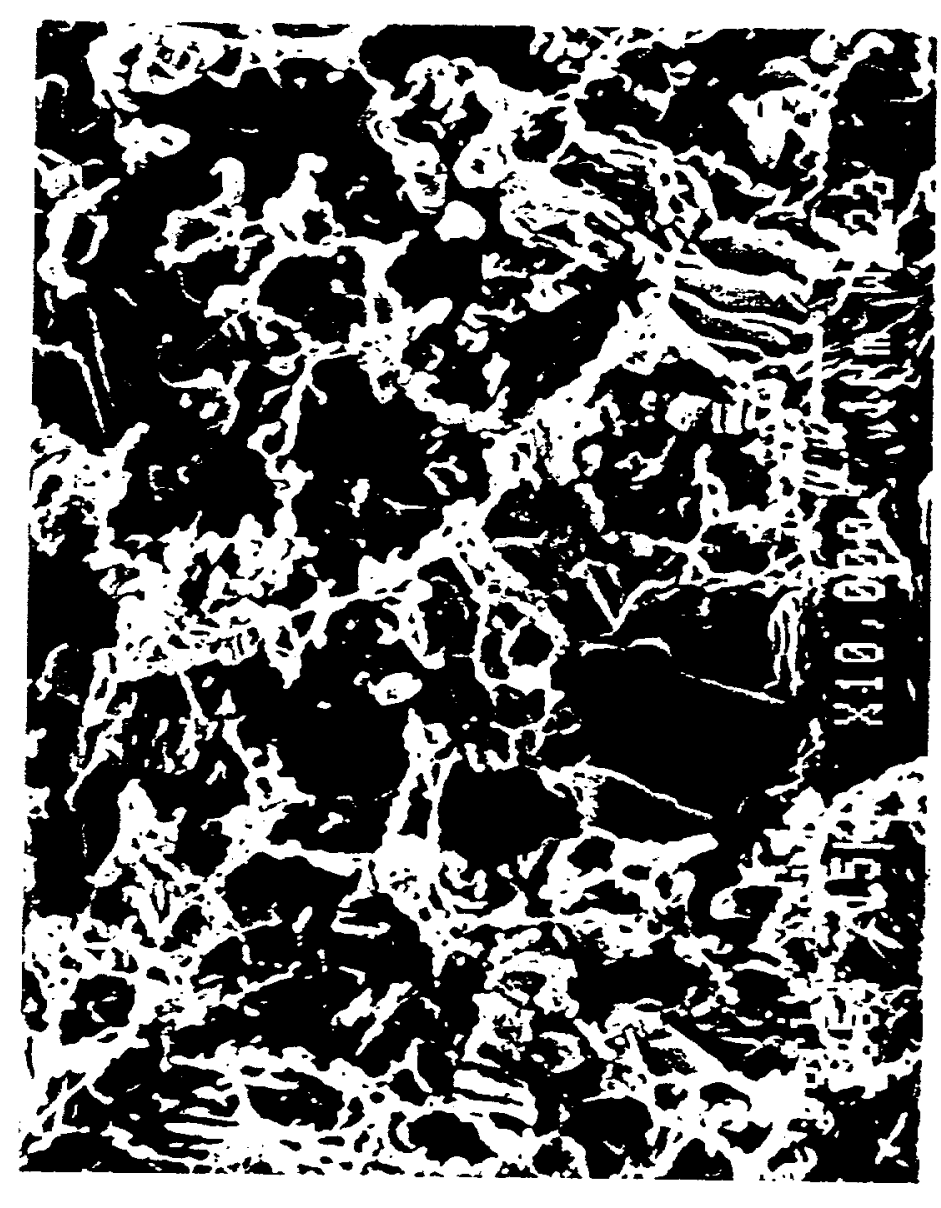




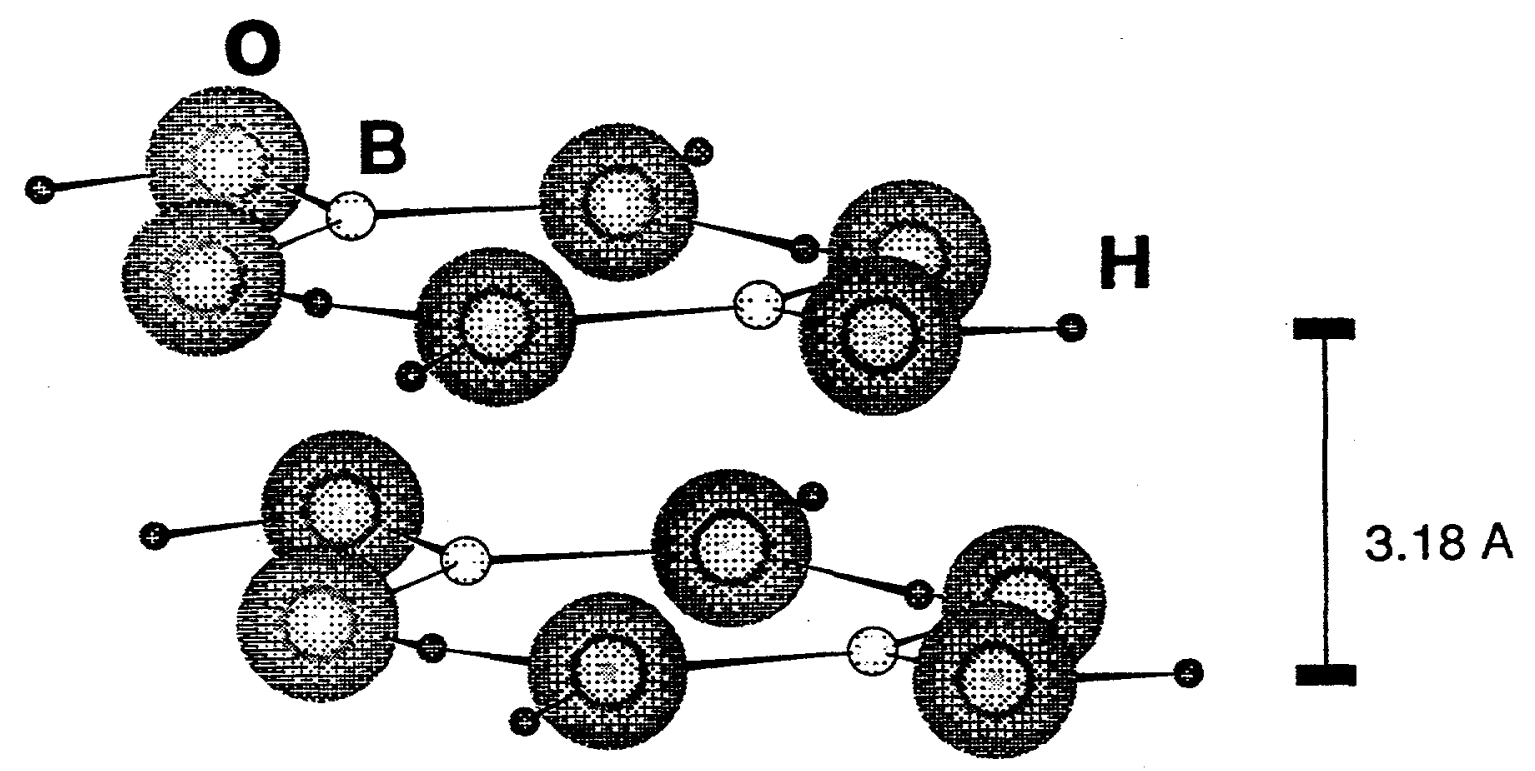

INTERLAYER BONDING : van der Waals

Figure 9 Layered crystal structure of boric acid 